\title{
Forma Livre
}

\section{CARTAS PARA MARCELO DENNY}

\section{Marcelo dos Santos Prudente}

\section{Marcelo dos Santos Prudente \\ Universidade de São Paulo; Mestrando em Artes} Cênicas; Poéticas do Afeto: performance participativa no espaço urbano e na escola pública (pesquisa em andamento). Área de estudo: Texto e Cena. Orientadores: Marcelo Denny de Toledo Leite e Ferdinando Martins. Artista multimidia e arte-educador pelo Governo do Estado de São Paulo (2012). Fundador e artista criador do Atelier Transe. Integrou o CPT (Centro de Pesquisas Teatrais) dirigido por Antunes Filho. Atuou na exposição Terra Comunal, da artista Marina Abramovic, no SESC Pompeia (2015). Integrou e

fundou o Desvio Coletivo (2011 - 2016) e atual integrante do Pronto Sorrir, grupo de intervenções artísticas em hospitais pediátricos. 


\section{Resumo}

Destina-se esta correspondência a todos os corpos que foram atravessados pela presença performativa do investigador, professor e artista Marcelo Denny. Corpos vibráteis ${ }^{1}$, que se multiplicaram por meio de uma cartografia sentimentaf. Tracejados, rabiscados e respingados pelo seu ímpeto de urgência de vida.

Palavras-chave: Marcelo Denny; Performance Art; Corpo; Espinho

"Acho que a vida é urgente, como o Mario Quintana falava - precisamos sempre otimizar nossas ações em planos diferentes -pra dar e fazer sentido tanto esforço envolvido". (DENNY, Marcelo. Informação verbal)

Esta pequena cartografia, é uma tentativa de navegar em meio a imensidão de um "mar" chamado Marcelo Denny. Por ele, vários barquinhos foram abarcados, guiados por lampejos com claror. Refiro-me neste último trecho ao livro da autora Beatriz Carneiro, Relâmpagos com Claror, que reflete sobre o artista como um alguém que sabe alcançar o raio e usá-lo ao seu proveito, com um relâmpago, que ilumina por segundos a existência sua e de outros. Denny, era esse artista, professor, provocador de si, do outro, do mundo.

Conheci o querido Marcelo Denny quando tinha nove anos de idade, através do espetáculo itinerante "O Auto da Barca do Inferno", em nossa cidade natal, Pindamonhangaba. Foi um divisor de águas. O espetáculo, que se iniciava em um trem na estação ferroviária com destino a Campos do Jordão, nos levava a uma olaria da cidade. A comunidade, que até então tinha dificuldades de ter acesso à cultura e ao teatro, pois a região era distante do centro, também se envolveu para realizar aquele acontecimento nunca visto

\footnotetext{
${ }^{1}$ Esse conceito de Suely Rolnik de cartografia ou de como pensar com o corpo vibrátil, esteve presente em muitas orientações que eu tive do, então querido amigo artista professor doutor Marcelo Denny, que faleceu em agosto de 2020.

2 Suely Rolnik: Cartografia Sentimental, Transformações contemporâneas do desejo, Editora Estação Liberdade, São Paulo, 1989.
} 
até então em nossa cidade. Seu discurso artístico e criativo já trazia uma estética cenográfica visceral, deslocando nossos corpos para uma experiência sensorial muito grandiosa. As arquibancadas eram de madeira (feitas especialmente para o espetáculo), os figurinos e adereços eram uma extensão plástica e muito característica de seu trabalho manual. Corpos pintados, adornos majestosos, e um elenco com muito fogo no $\mathrm{c}^{*}$, como ele sempre dizia. Depois dessa vivência o movimento teatral da cidade nunca mais foi o mesmo e o diálogo sobre possibilidades de refletir a partir do corpo e suas camadas foram se estendendo em seu trabalho artístico juntamente com sua vida, que era sempre um celebrar ritualístico. As outras gerações que vieram após esse acontecimento, como eu, foram também se apropriando dessa potência dionisíaca.

Marcelo, sempre foi presente nas movimentações artísticas da cidade e região, sendo um dos fundadores do Teatro Galpão de Pindamonhangaba, COOTEPI. Neste palco e espaço suas percepções e indagações sobre o corpo como metáfora da sociedade, foram expressadas, dialogadas e compartilhadas por muitos anos. Vozes que ainda ecoam neste movimento de multiplicação, permeados também pelo Desvio Coletivo e Teatro da Pomba Gira, e sua trajetória como docente na Universidade de São Paulo. Convivemos e criamos muito nos últimos anos. Porém em meio ao vazio da saudade, em meio as memórias tão significativas, que em seus primeiros momentos eram contemplativas, em minha infância e adolescência, gostaria de partilhar a experiência sobre esse grande professor e orientador da minha investigação no mestrado. Essa travessia só foi possível pela generosidade do Denny. Suas orientações não eram apenas transgressoras, eram subversivas, e aconteciam de múltiplas maneiras. Desde uma disciplina ministrada por ele, até a beira de uma piscina com cuba libre cheio de amigos em volta ou num almoço de domingo com cerveja junto de comentários sobre os homens bonitos e interessantes que passavam pela rua. Em todo esse movimento, que também era regado por muito estudo e conhecimento que ele fazia questão de compartilhar, não havia separação entre a vida pessoal, docente ou artística, mas sim pulsão de vida. Fazia questão de emprestar seus livros, permitia que grifássemos trechos, tinha uma biblioteca incrível, um 
dos seus maiores orgulhos. Atrevo-me inclusive a dizer que sua existência, foi e é, pois ele vive em nós, sua maior performance. É raro encontrarmos tantas possibilidades afetuosas persistentes neste sistema opressor em que vivemos.

Em 2019 tive o privilégio de ser convidado por ele junto do querido orientando performer Thiago Camacho ${ }^{3}$ para participarmos da disciplina de graduação Práticas Performativas, pelo departamento de Artes Cênicas da USP. Foi um diálogo sobre nossas investigações de mestrado artísticas e reflexão sobre o ensino público. A ação intitulada Aula Invertida faz parte das criações que venho desenvolvendo sobre o corpo na escola pública, por meio de programas performativos participativos. Dois professores da rede pública vestidos com um avental tela branca. Giz de lousa para os participantes estudantes, docentes. A pergunta disparadora na lousa da sala de aula: "Qual a sua memória da escola?". Todos são convidados a compor o quadro, a lousa, seus corpos. Revisitam memórias, ressignificando afetos. Em seguida os performers apagam a lousa com seus aventais brancos, e com seus corpos. São borrados pelas palavras e cores do giz de lousa. São atravessados por este rito que propõe criar novas narrativas para a vivência no ensino público. A cada apagar (não apagamento), uma nova pergunta surge. "Quanto vale um professor, professora?" E assim por diante.

\footnotetext{
${ }^{3}$ Ator, Performer e Professor de artes, teatro, literaturas e línguas. Doutorando (2020) e Mestre pelo Programa de Pós-graduação da Escola de Comunicações e Artes - a ECA, da Universidade de São Paulo (USP). 2017-2019. Graduado pelo curso de Arte-Teatro da Universidade Estadual Paulista. (UNESP). Possui graduação em Letras - Português, Inglês e Literatura pela Universidade Paulista (2009). Desenvolve um trabalho pessoal e independente de pesquisa com registros e produções da Performance, entre os quais estão vídeos e fotografias. Professor de Línguas Portuguesa e Inglesa, Artes, Teatro, e de Literaturas no Ensino Fundamental II e Médio das redes municipal e estadual de São Paulo (desde 2010). Foi membro participante-colaborador do grupo de teatro e performance Desvio Coletivo.
} 


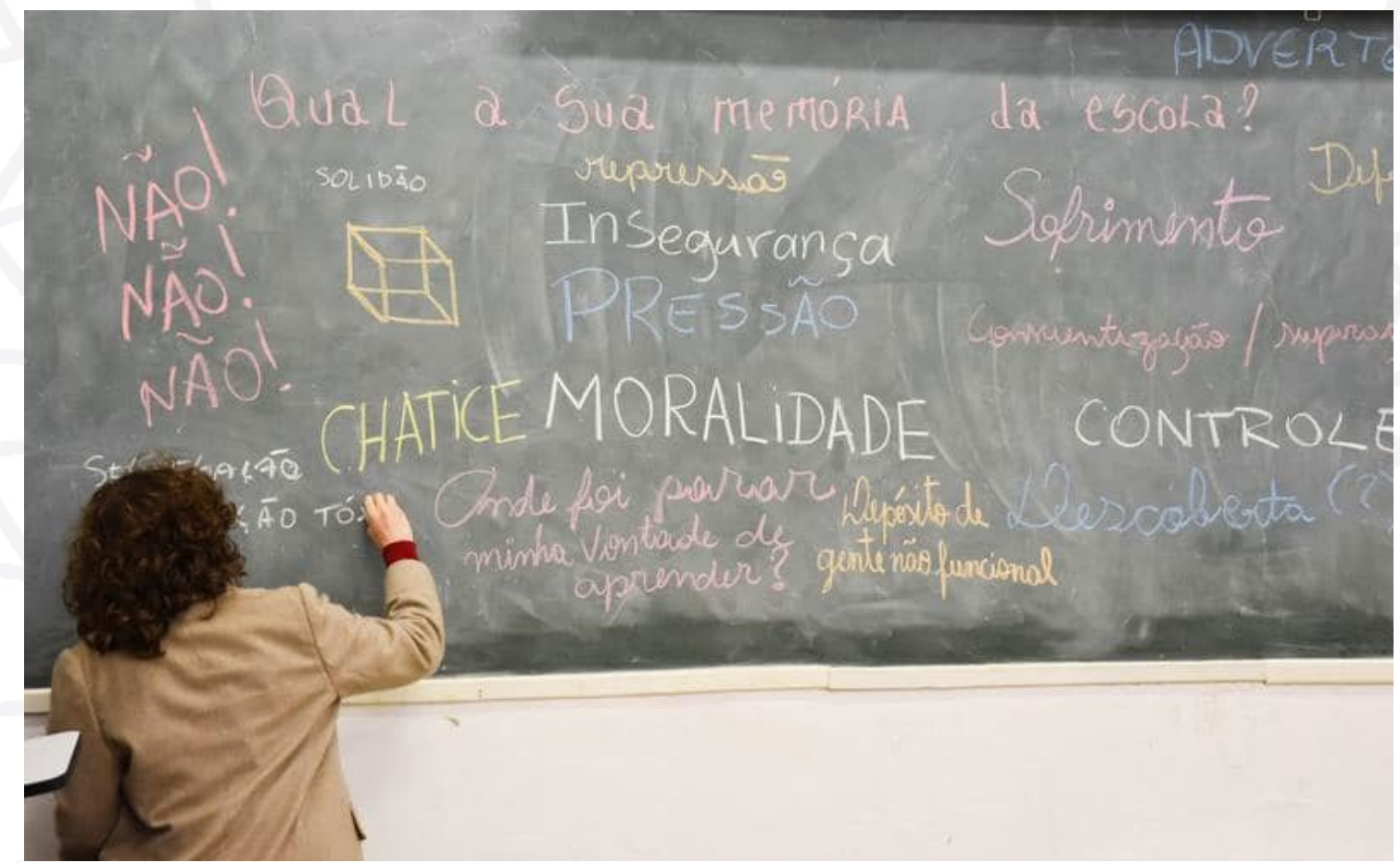

Aula Invertida. Participação Thiago Camacho. Disciplina Práticas Performativas. Docente Marcelo Denny. Imagem de Pedro Orlando. 2019

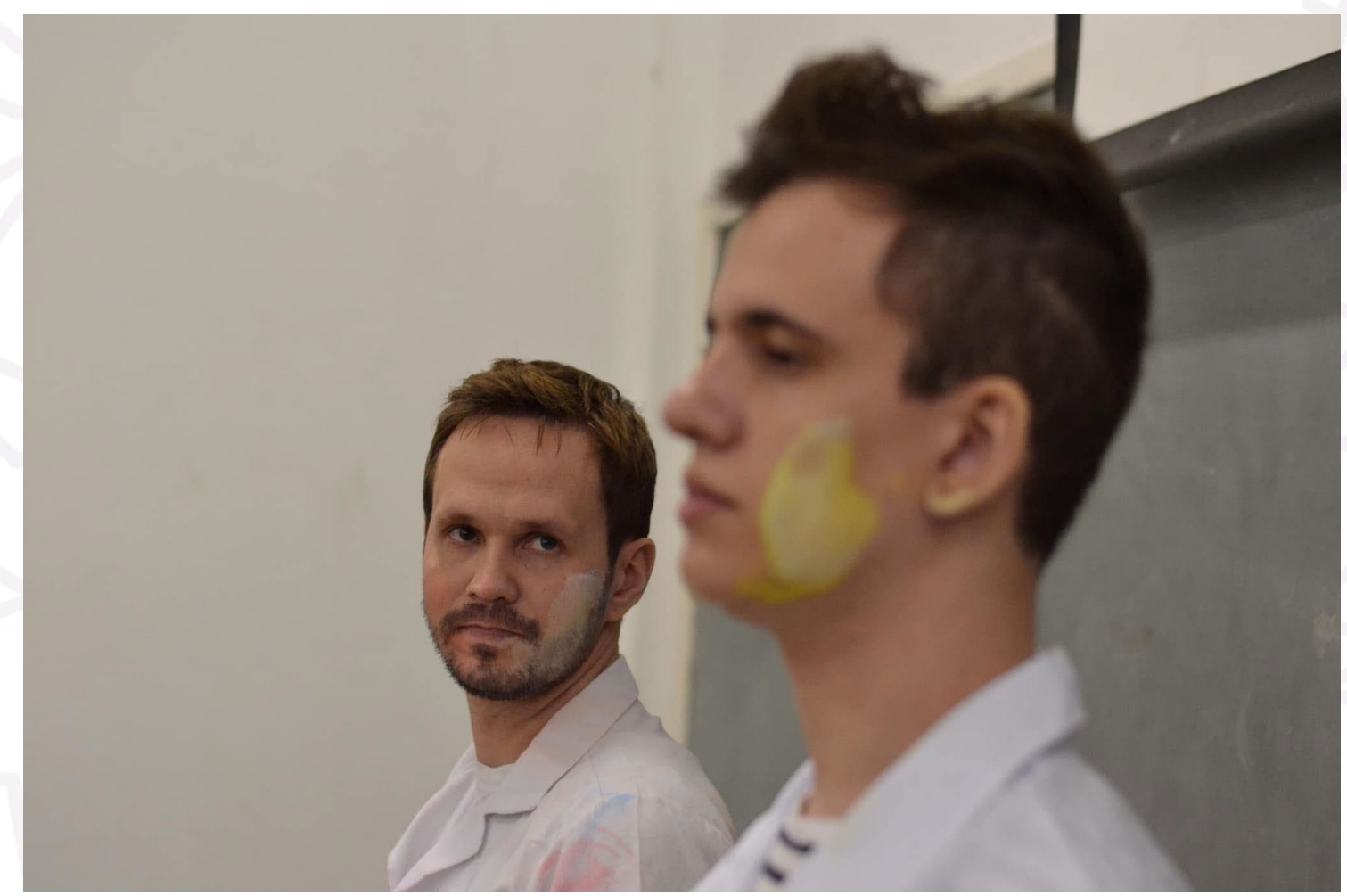

Aula Invertida. Participação Thiago Camacho. Disciplina Práticas Performativas. Docente Marcelo Denny. Imagem de Pedro Orlando. 2019. 


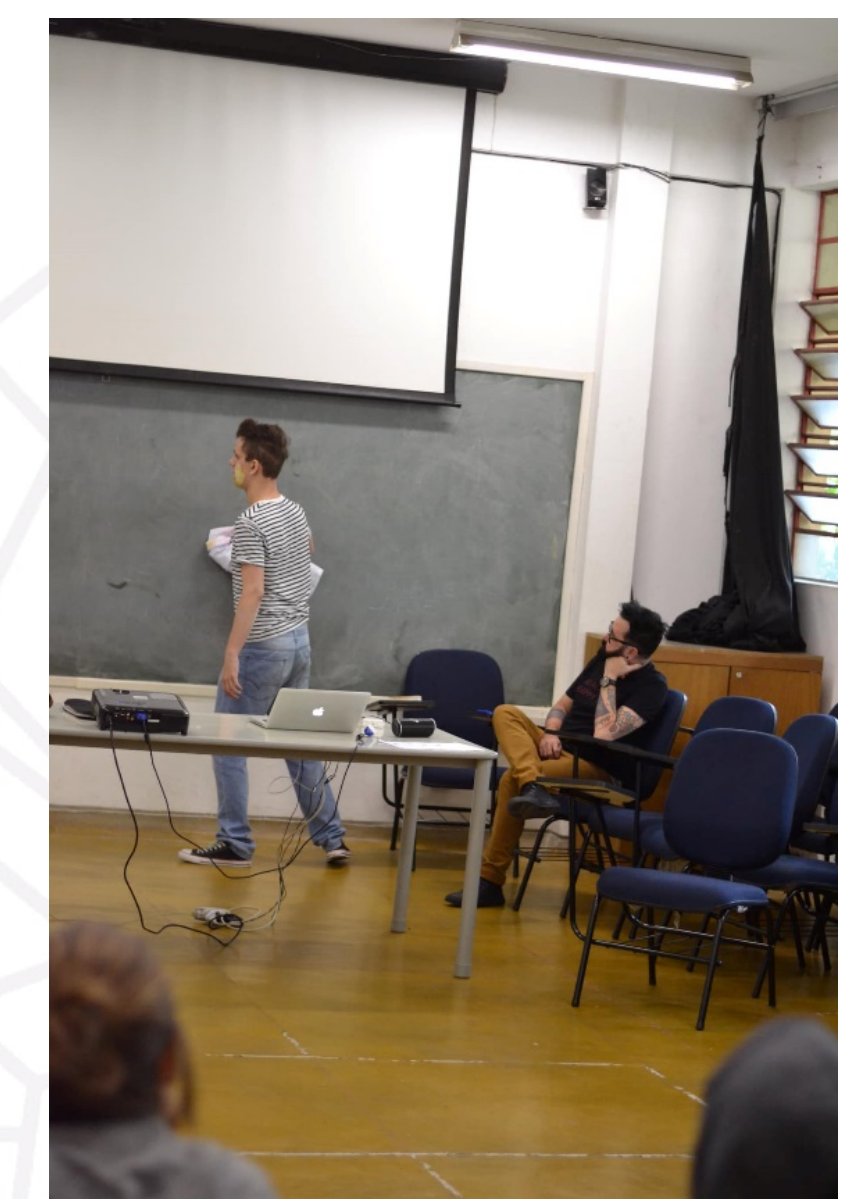

Aula Invertida. Participação Thiago Camacho. Disciplina Práticas Performativas. Docente Marcelo Denny. Imagem de Pedro Orlando. 2019.

Nossos corpos se entrelaçaram, conterrâneos, artistas, professores, xarás. Sua existência e desejo de vida ocupou muitos territórios. Sua inquietação sempre partia da pergunta: Qual é o espinho de peixe entalado na sua garganta? Com essa provocação nos proporcionava uma cultura e visão de mundo baseadas em nossas potências artísticas através dos nossos corpos, das nossas autobiografias, das nossas próprias experiências, que se fizeram performativas pela consciência que tivemos de si, do outro, de todos.

\section{Qual o espinho de peixe entalado na minha garganta?}

Durante os dois últimos anos enfrentei um tratamento de saúde muito profundo. Uma experiência de quase morte. Denny esteve ao meu lado todos os dias, um dos meus melhores amigos. Minhas idas aos médicos eram muito intensas. 
Em 27 de agosto de 2020

Fui fazer um dos meus exames de rotina na rua Itapeva, muito próximo à casa do Denny. E passei por lá, para the devolver o livro que me emprestou intitulado Happening (LEBEL,1969) desde o começo da investigação. Ele estava radiante com a biblioteca pronta. Mostrou-me, batemos um papo e foi a última vez que o vi fisicamente, nos dias seguintes conversamos por celular, como de hábito.

Em 31 de agosto de 2020

Meu telefone toca logo pela manhã. Eram mais ou menos 8:30. Em seguida fui para o hospital Santa Casa de Misericórdia, perto da minha casa, no bairro Santa Cecília, em São Paulo. Chego e tenho a notícia de que meu querido amigo, parceiro de criações artísticas e de vida, meu orientador havia morrido. De todos os espinhos que passei durante os últimos dois anos, como meu tratamento profundo de saúde, este, a saudade, é o que está mais entalado em minha garganta.

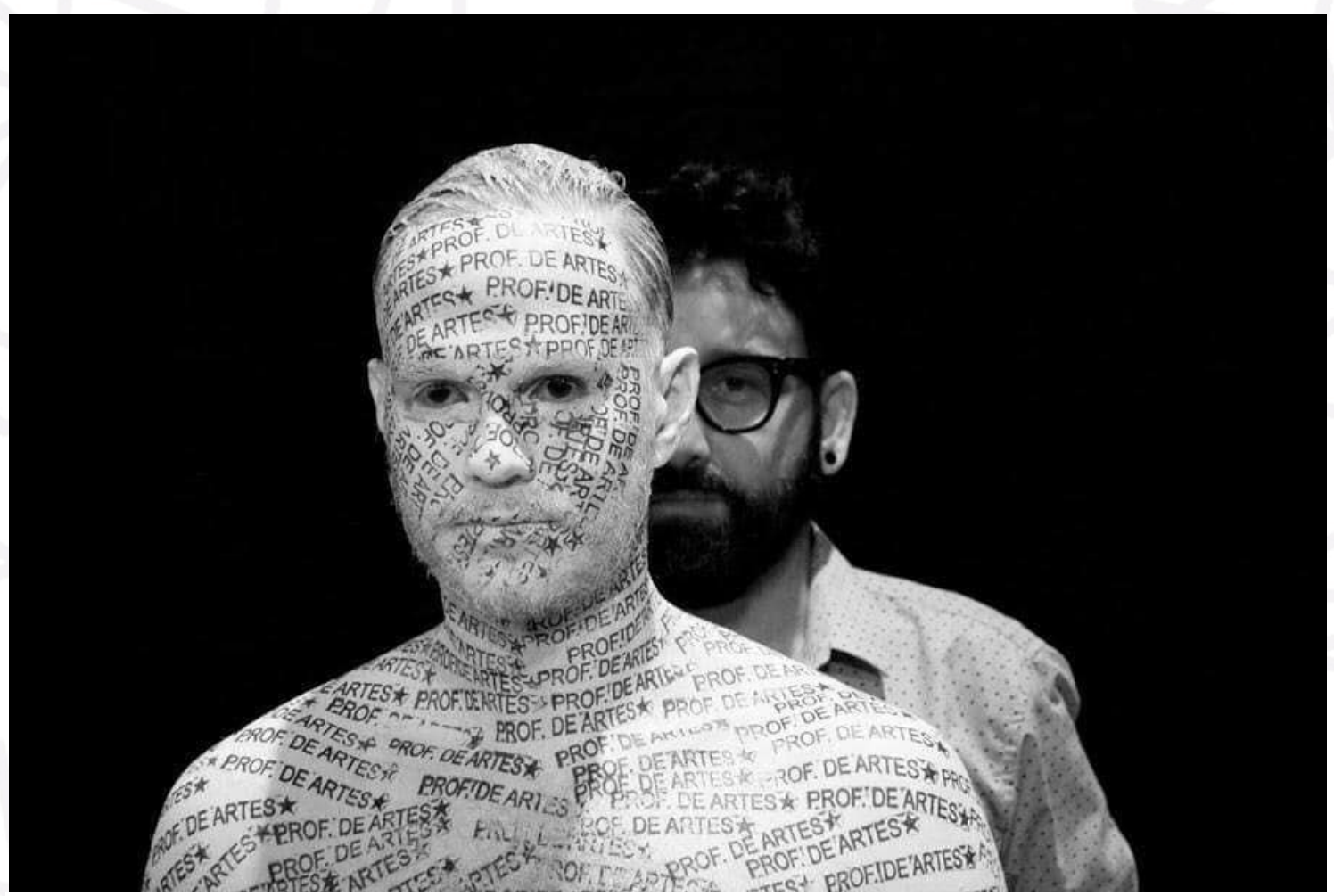

Arte Carimbada. Disciplina Arquiteturas do Corpo e Coralidades. Docentes Marcelo Denny e Marcos Bulhões. Imagem de Hélio Beltrano. 2016. 
Esta é uma singela homenagem ao meu grande amigo Marcelo Denny. Abaixo, convido o leitor que procure no caça palavras por vestígios poéticos sobre sua presença. tão importante para os amigos, artistas e para a arte no Brasil.

Assim que formar as palavras, vire o desenho na horizontal e verá um formato de espinho de peixe. Ele se manterá atravessado em nossas gargantas, preenchendo um vazio que permanecerá.

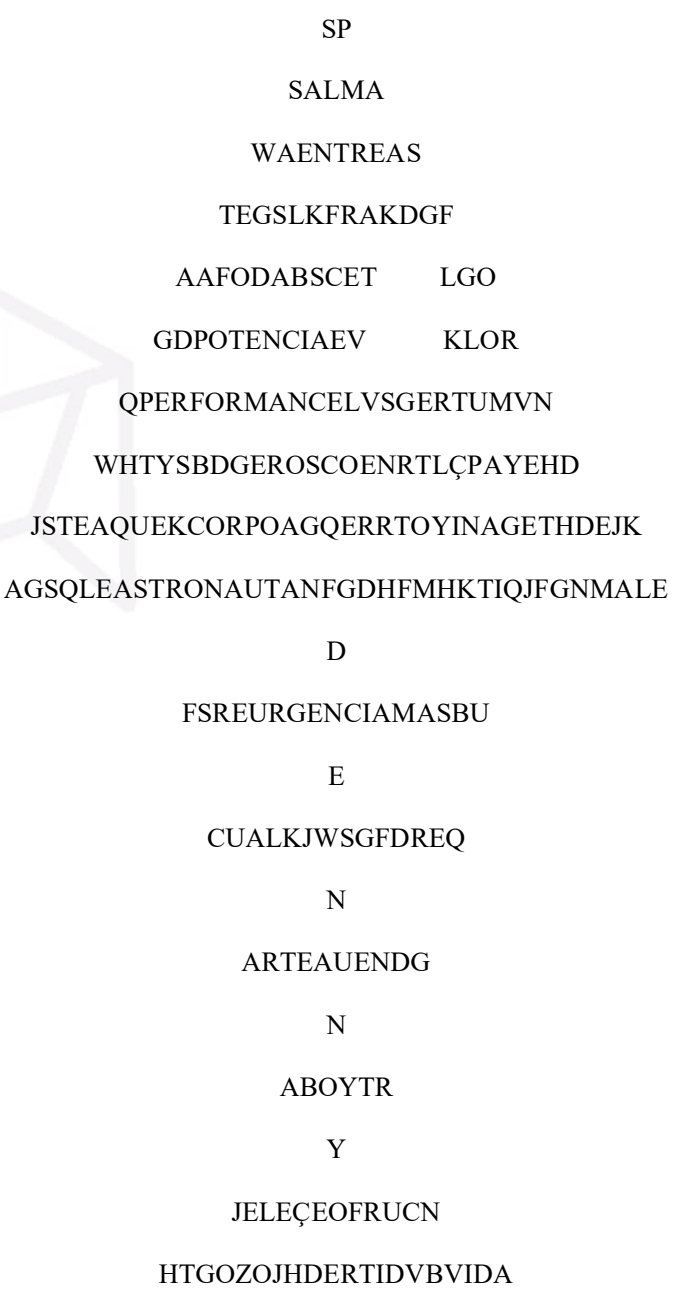

BSNEHCUBALIBREMNAJUIOPSSDGFTELALGT 


\section{REFERÊNCIAS BIBLIOGRÁFICAS}

CARNEIRO, Beatriz Scigliano. Relâmpagos com claror: Lygia Clark e Hélio Oiticica, vida como arte. São Paulo: Imaginário: FAPESP. 2004.

ROLNIK, Suely. Cartografia sentimental: transformações contemporâneas do desejo. São Paulo: Estação Liberdade, 1989. 